\title{
Atividades com o oral nos anos iniciais do ensino fundamental
}

\author{
Oral classroom exercises in elementary school
}

\author{
Aline Lopes da Fonseca \\ Universidade Federal Rural de Pernambuco - UFRPE
}

Gustavo Henrique da Silva Lima

Universidade Federal Rural de Pernambuco - UFRPE

Sara Talita Cordeiro Vilela

Universidade Federal Rural de Pernambuco - UFRPE

DOI: https://doi.org/10.5902/2176148538835

Resumo: o presente trabalho tem como objetivo compreender a natureza das atividades com o oral nos anos iniciais do ensino fundamental. De forma mais específica, identificar: a) quais atividades com o oral são realizadas na sala de aula; b) como tais atividades são organizadas; c) quais aspectos do oral são contemplados nessas atividades. Como aporte teórico, foram utilizados os estudos de Schneuwly e Dolz (2004), Marcuschi (2005) e Cavalcante e Melo (2007), entre outros. A metodologia utilizada consistiu na aplicação de questionário e de um estudo de caso (LÜDKE e ANDRÉ, 2012) com uma docente dos anos iniciais do ensino fundamental. Os resultados evidenciaram a prevalência de dois tipos de atividades com o oral na sala de aula, a saber: leitura em voz alta e apresentação de trabalho. Verificamos, ainda, que, nessas atividades, a professora revelou uma preocupação constante com aspectos paralinguísticos e cinésicos da fala.

Palavras-chave: Oralidade. Atividades. Ensino.

Abstract: this work aims to investigate how oral classroom exercises goes on elementary school group. Specially, it aims to identify: a) how oral classroom exercises are conducted in the classroom; b) how such exercises are organized; and c) which oral aspects are emphasized in these exercises. Our theoretical framework was based on the studies of Schneuwly and Dolz (2004), Marcuschi (2005) and Cavalcante and Melo (2007), among others. The methodology consisted of the application of a questionnaire and a case study with a teacher (LÜDKE and ANDRÉ, 2012). The results pointed to two types of oral exercises in the classroom: reading aloud and work presentation. We also verified that the teacher did some observations about the students presentation. The comments were related to some paralinguistic and cineseic aspects of oral speech.

Keywords: Oral. Exercises. Teaching. 


\section{Pra começo de conversa...}

Pesquisas sobre o ensino da oralidade no cenário nacional têm se vol-

Aline Lopes da

Fonseca

Gustavo

Henrique da

Silva Lima

Sara Talita

Cordeiro Vilela

486 tado para o currículo (MAGALHÃES, 2007), o livro didático (COSTA-MACIEL e BILRO, 2015) e os saberes docentes (COSTA-MACIEL e BARBOSA, 2012). Diferentemente dessas pesquisas, o presente estudo tem como foco as atividades com o oral na prática docente: sua natureza, sua organização e sua avaliação. Desse modo, neste artigo pretendemos ampliar as reflexões acerca do oral como objeto de ensino, por ser tratar de uma modalidade da língua ainda pouco compreendida por muitos docentes.

Nesse sentido, o nosso foco reside nas atividades envolvendo o eixo da oralidade nos anos iniciais do Ensino Fundamental, já que pesquisas acerca do trabalho com o oral na escola ainda são bastante escassas. Segundo Beserra e Lima (2012), “(...) materiais de apoio para o professor, que tratam especificamente da língua falada, são menos abundantes." Tal aspecto reforça ainda mais necessidade de estudos voltados ao fazer docente, de modo que possamos pensar em possibilidades didático-metodológicas para um tratamento mais sistemático do oral em sala de aula. Assim, pretendemos, aqui, responder às seguintes questões: Quais atividades com o oral são priorizadas nos anos iniciais do ensino fundamental? Como elas são organizadas? Quais dimensões do oral são focalizadas nessas atividades? Diante de tais questionamentos, o presente estudo tem como objetivo compreender a natureza das atividades com a oralidade nos anos iniciais do ensino fundamental e, de forma mais específica, identificar: a) quais são as atividades com o oral são realizadas na sala de aula; b) como tais atividades são organizadas e c) quais dimensões do oral são focalizadas nessas atividades.

Iniciaremos este artigo com algumas considerações teóricas acerca da problemática envolvendo o ensino do oral nas escolas e, na sequência, apresentaremos algumas sugestões para o trabalho com esse eixo de ensino à luz de alguns estudos já desenvolvidos sobre o tema. Por fim, discutiremos os dados referentes às atividades com o oral nas aulas.

\section{A problemática do oral como objeto de ensino}

No princípio era o verbo. Os ensinamentos, os valores, a cultura, tudo era transmitido oralmente, sem que houvesse qualquer garantia de registro para a posteridade. Com o passar do tempo histórico, outras formas de registro foram sendo desenvolvidas pelo homem, inicialmente 
através de pinturas rupestres em cavernas, mais tardiamente, por meio da escrita em papel e, na era da modernidade, em tela de computadores, tablets e celulares.

A escrita sempre teve um papel de destaque na sociedade moderna, sendo utilizada como principal meio de registro, o que, possivelmente, justifica a ênfase que tem sido dada ao seu ensino nas escolas. Por outro lado, a oralidade (que era o verbo) continua sendo negligenciada, pois muitos professores ainda a veem como um momento espontâneo de fala, sem qualquer importância para a aprendizagem dos alunos. Ou seja, "embora a linguagem oral esteja bastante presente nas salas de aula e nas mais diferentes práticas sociais fora dela, “[...] afirma-se que ela não é ensinada, a não ser incidentalmente, durante atividades diversas e pouco controladas" (DOLZ, SCHNEUWLY e HALLER, 2004, p.149).

Atividades com o oral nos anos iniciais do ensino fundamental

[...] o ensino escolar da língua oral e de seu uso ocupa atualmente um lugar limitado. Os meios didáticos e as indicações metodológicas são relativamente raros; a formação dos professores apresenta importantes lacunas (p. 150).

Ao refletir sobre o trabalho com a oralidade no contexto educacional brasileiro, Antunes (2003) também afirma que há uma visão equivocada em relação à fala, a qual geralmente é vista como o lugar da violação das regras da gramática: tudo o que é "erro" na língua acontece na fala; na fala é permitido falar errado. De acordo com a autora, esse conceito distorcido sobre a oralidade precisa ser corrigido para que a atual omissão da fala como objeto de exploração sistemática no trabalho escolar seja repensada. Estudos recentes também têm reiterado essa problemática envolvendo o tratamento do oral na sala de aula, como, por exemplo, a falta de compreensão dos docentes sobre as atividades voltadas para desenvolver a oralidade; a falta de compreensão dos alunos de que atividades orais também visam ensinar e aprender

1 Os autores fazem uma abordagem do ensino do oral a partir do contexto suíço-francófono, mas pesquisas no cenário educacional brasileiro têm reafirmado as constatações feitas por esses autores. 


\section{Aline Lopes da}

Fonseca

Gustavo

Henrique da

Silva Lima

Sara Talita

Cordeiro Vilela

determinadas competências; a falta de planejamento do professor para trabalhar a oralidade; a variação linguística e o próprio livro didático, que não dedica o tratamento adequado ao eixo da oralidade etc (COSTA-MACIEL, 2011).

Em decorrência disso, o trabalho com oral continua quase sempre restrito a situações didáticas que envolvem conversas espontâneas ou "debates" na sala de aula sobre algum texto ou tema controverso. Tal aspecto, a nosso ver, pode ser explicado, dentre outras variáveis, pela escassez de orientações teórico-metodológicas que explicitem, com clareza, o que é a oralidade e quais as possibilidades de trabalhá-la na sala de aula,

\section{Desatando alguns nós: as dimensões ensináveis do oral}

O ensino da expressão oral na sala de aula vai muito além de rodas de conversas sobre um texto ou tema qualquer, de colocar o aluno para falar diante da turma ou de realizar uma leitura em voz alta. $O$ estudo sistemático da fala envolve questões sobre discriminação linguística, preconceito, controle social, formal/informal, variações relativas aos falares regionais e culturais, que "[...] tornam-se centrais no ensino de língua e ajudam a formar a consciência de que a língua não é homogênea nem monolítica" (MARCUSCHI, 2005, p. 24). Assim, para fazer com que o aluno possa refletir e utilizar a modalidade oral da língua de forma consciente e produtiva, a escola precisa livrar-se de alguns mitos, tais como o de que existe uma única forma 'certa' de falar - a que se parece com a escrita - o de que a escrita é o espelho da fala - e, sendo assim, seria preciso 'consertar' a fala do aluno para evitar que ele escreva errado (MARCUSCHI, 2005, p. 26).

o primeiro passo é superar a dicotomia fala e escrita, segundo a qual o oral é sempre visto como o lugar do erro ou do caos linguístico (MARCUSCHI, 2005). Nessa perspectiva, o ensino consciente do oral na escola requer, a priori, o reconhecimento das especificidades dessa modalidade da língua e suas formas de manifestação em diferentes contextos enunciativos. Além disso, é preciso também que o professor tenha domínio e clareza das dimensões ensináveis do oral e das habilidades que, efetivamente, precisam ser desenvolvidas pelos alunos. Para isso, é importante que, ao longo do processo de escolarização, o aluno se familiarize com gêneros orais do domínio público que possibilitem a eles desenvolverem competências do oral que, em geral, não são apreendidas na vida cotidiana. Tal aspecto já era preconizado pelos Parâmetros Cur- 
riculares Nacionais de Língua Portuguesa, segundo os quais cabe a escola "ensinar o aluno a utilizar a linguagem oral nas diversas situações comunicativas, especialmente nas mais formais [...]." (BRASIL,1997, p. 27), muito embora esse documento não deixe claro como isso poderia efetivamente ser feito na sala de aula.

Assim, impõe-se a necessidade de um estudo direcionado, seja por meio de sequências didáticas ou outras propostas metodológicas, considerando que certos conhecimentos e certas habilidades devem ser desenvolvidas por meio de trabalhos mais sistemáticos e de reflexão mais consistente sobre as práticas de linguagem que envolvem o discurso oral. Um caminho possível é mostrar ao aluno a importância de se dominar, de maneira competente, a fala para a participação social (MARCUSCHI, 2005). Nesse sentido, o papel do professor não seria o de apontar os "erros" da

Atividades com o oral nos anos iniciais do ensino fundamental fala, mas criar situações didáticas na sala de aula para que os alunos percebam as diferentes manifestações do oral na vida pública, levando-os, por conseguinte, a compreender e a produzir discursos que atendam a determinados propósitos comunicativos, em contextos específicos.

Outro aspecto a ser considerado no ensino do oral é que, quando falamos, não utilizamos apenas a voz, ou seja, a produção oral é acompanhada por todo um aparato corporal, como, por exemplo, o gesto, a troca de olhares e a expressão facial, tal como apontam Dolz, Schneuwly, Pietro e Zahnd (2004). Sob esse viés, o trabalho com a oralidade na sala de aula não deve prescindir da observância de tais aspectos, uma vez que eles são determinantes na produção dos efeitos de sentido, ao mesmo tempo em que buscam atender a propósitos comunicativos específicos de determinados gêneros orais.

Tomando como referência alguns estudos desenvolvidos pelo linguista Luiz Antônio Marcuschi sobre fala e escrita ${ }^{2}$ e a discussão sobre o oral como objeto de ensino em Schneuwly e Dolz (2004), Melo e Cavalcante (2007) elaboraram três categorias de análise do desempenho oral, a saber: aspectos linguísticos, extralinguísticos, paralinguísticos e cinésicos. Tais aspectos, segundo as autoras, são interdependentes, de modo que: "os aspectos extra e paralingüísticos interferem diretamente no funcionamento daquilo que é de natureza estritamente lingüística (verbal)" (MELO e CAVALCANTE, 2007, p. 83).

2 No texto, as autoras fazem menção a um Curso ministrado pelo Professor Luiz Antônio Marcuschi sobre Fala e Escrita, no ano de 2002. 
A primeira categoria (o linguístico), segundo as autoras, diz respeito à construção sintática e às estratégias de interação do oral que

Aline Lopes $\mathrm{da}$

Fonseca

Gustavo

Henrique da

Silva Lima

Sara Talita

Cordeiro Vilela

490 envolvem o uso de marcadores conversacionais, repetições, paráfrases, hesitações, digressões, estratégias de polidez etc. A segunda (o extralinguístico) contempla os elementos do contexto físico e social que interferem diretamente na expressão oral. Consistem, pois, nos elementos do entorno, tais como os participantes envolvidos, inclui-se nesse caso o auditório, o grau de envolvimento e cooperação entre esses participantes e o tema ou assunto fixado, que determinarão o que será dito e como será dito. Por fim, a terceira e última categoria (o paralinguístico e o cinésio) estaria associada aos recursos prosódicos da fala (entonação, ritmo, qualidade da voz etc) e os relacionados à expressão corporal e facial, tais como aceno ou outras formas de gesticulação, postura, olhares etc (cf. MELO e CAVALCANTE, 2007).

Leal, Brandão e Lima (2012), por sua vez, também apresentam uma alternativa metodológica para o tratamento do oral como objeto de ensino na escola. De acordo com as autoras, quatro dimensões precisam consideradas no fazer pedagógico para o desenvolvimento da linguagem oral, a saber: valorização de textos de tradição oral; oralização do texto escrito ${ }^{3}$; variação linguística e relações entre fala e escrita e produção e compreensão de gêneros orais.

A valorização de textos de tradição oral tem seu foco na cultura linguística dos alunos e de sua comunidade e poderia ser trabalhada através de atividades de compreensão e produção de gêneros, como receitas culinárias locais, contos de assombração, lendas urbanas, brincadeiras, parlendas, trava-línguas e as cantigas, que vêm sendo passados de geração para geração. A oralização do texto escrito, por sua vez, é uma das atividades mais comuns no espaço escolar e focaliza a necessidade de o aluno se expressar em voz alta, fazendo uso adequado de pausas e gestos durante a fala. Algumas atividades mais comuns dessa natureza são a leitura em voz alta de textos escritos, a recitação de poemas e a apresentação teatral, que favorecem o desenvolvimento algumas habilidades típicas da expressão oral. Já a produção e a compreensão de gêneros orais, como o próprio termo enfatiza, refere-se a atividades de produção e compreensão de textos orais de diferentes esferas

3 Esse tipo de atividade não é um ponto pacífico entre os estudiosos da oralidade. Neste estudo, assumiremos a posição de Leal, Brandão e Lima (2012) pelas razões que apresentaremos mais adiante. 
públicas e envolve desde a análise das características da linguagem e das formas de organização até o funcionamento de diferentes gêneros orais, dando a devida atenção ao tempo da fala, à escuta, ao respeito a fala do outro, favorecendo, assim, o desenvolvimento de capacidades de linguagem que atendam a diferentes finalidades comunicativas. E, no que diz respeito à dimensão variação linguística e relações entre fala e escrita, é essencial oportunizar aos alunos uma reflexão sobre as variações linguísticas na fala, fazendo com que eles se conscientizem sobre os diferentes modos de falar.

\section{Aspectos metodológicos}

O estudo realizado seguiu uma abordagem qualitativa (LÜDKE e ANDRÉ, 2012). Os dados aqui apresentados foram gerados em duas etapas: inicial-

Atividades com o oral nos anos iniciais do ensino fundamental mente a partir da aplicação de um questionário a um grupo de 06 professoras $^{4}$ que lecionavam em turmas do $4^{\circ}$ e $5^{\circ}$ anos do Ensino Fundamental de três escolas da rede municipal de ensino de Garanhuns-PE, no ano de 2017. O objetivo era saber se as docentes desse nível de ensino costumavam trabalhar com o eixo da oralidade nas suas aulas, bem como quais tipos de atividades com o oral eram realizadas por elas em sala.

Considerando essas variáveis, selecionamos, para a etapa seguinte da pesquisa, uma professora ${ }^{5}$ para realização de um estudo de caso (LÜDKE e ANDRÉ, 2012), o qual ocorreu por meio de observações de algumas aulas em que, segundo a docente, as atividades com o oral por ela mencionadas seriam vivenciadas com os alunos. Foram dois momentos de observações de atividades envolvendo o oral: no primeiro dia, com apresentações de trabalho sobre as regiões do Brasil, em que os alunos foram divididos em grupos para falar sobre costumes, cultura e outras características. No segundo dia, a atividade foi com a leitura em voz alta, com um livro de lendas e cantigas do folclore brasileiro.

\section{O lugar do eixo da oralidade nas aulas}

Quando questionadas sobre a frequência com que exploravam o eixo da oralidade nas suas aulas, metade das professoras pesquisadas afirmaram que o trabalho com esse eixo na sala de aula é contínuo. As respostas das docentes foram sistematizadas no gráfico abaixo:

4 Por questões éticas, as professoras serão aqui identificadas como P1, P2, P3, P4, P5 e P6.

5 Os critérios para a escolha dessa professora serão explicitados mais adiante. 


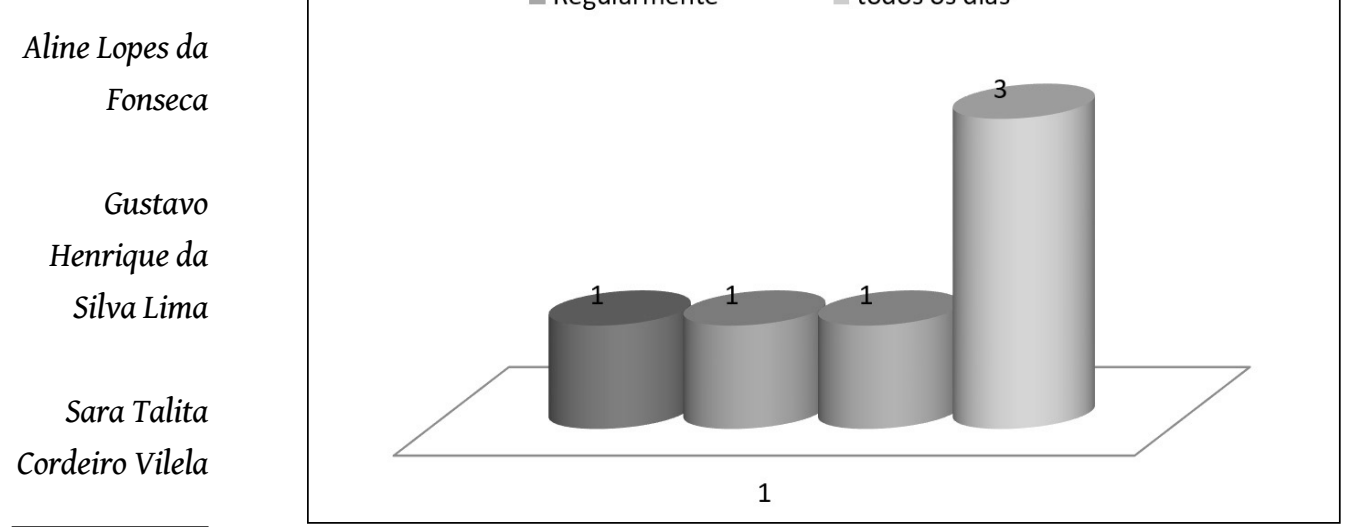

492 GRÁFICO 1: o lugar da oralidade no cotidiano escolar

Como já dissemos, três das seis professoras informaram que a oralidade está presente em "todas as aulas". Esse foi, sem dúvidas, um dado que nos inquietou muito e, por essa razão, buscamos compreender de que forma esse oral se fazia presente nessas aulas, o que, por conseguinte, nos levou a investigar sobre quais eram as atividades realizadas por elas nesse eixo de ensino.

\section{As atividades com o oral na sala de aula}

As atividades com o oral na sala de aula nos revelaram um pouco acerca de como o eixo da oralidade tem sido materializado nas práticas das professoras dos anos iniciais do ensino fundamental. No quadro abaixo, apresentamos alguns tipos de atividades que, segundo as professoras, eram frequentes nas suas aulas:

QUADRO 01: atividades com o oral na sala de aula

\begin{tabular}{|c|c|c|c|c|c|c|}
\hline TIPOS DE ATIVIDADE & P1 & P2 & P3 & P4 & P5 & P6 \\
\hline Apresentação de trabalhos & $\mathrm{X}$ & $\mathrm{X}$ & & & & \\
\hline Leitura em voz alta & $\mathrm{X}$ & & $\mathrm{X}$ & & & \\
\hline Roda de Conversa & $\mathrm{X}$ & $\mathrm{X}$ & $\mathrm{X}$ & $\mathrm{X}$ & & \\
\hline Debates & & $\mathrm{X}$ & & & & \\
\hline Exposição de ideias & & & & & $\mathrm{X}$ & \\
\hline
\end{tabular}

Fonte: elaborado pelos autores. 
O quadro acima permitiu que identificássemos quais atividades com o oral, segundo as professoras, eram mais frequentes em sala de aula, a saber: apresentação de trabalhos (P1 e P2), leitura em voz alta (P1 e P3), rodas de conversa (P1,P2, P3 e P4), debates (P2) e exposição de ideias (P5). A P6 não fez referência a qualquer atividade, apenas nos informou que a oralidade está presente "em todas as atividades realizadas em sala", o que aponta para o fato de que, em seu fazer pedagógico, o oral parece ser apenas um recurso a serviço de outros eixos de ensino.

Verificamos que "a roda de conversa" foi o tipo de atividade mais mencionado pelas professoras. Esse dado nos serviu como um indicador de que o oral é, muitas vezes, abordado de forma incidental e por meio de atividades pouco controladas, tal como afirmam Schneuwly, Dolz e Haller (2004). Outras atividades apontadas pelas professoras foram "leitura em voz alta" e "apresentação de trabalhos". Entendemos que a leitura em voz alta ou oralização do texto escrito, como denominam alguns estudiosos, é uma atividade importante, pois, além de possibilitar que as crianças desenvolvam fluência da leitura, favorece o desenvolvimento de habilidades importantes para a expressão oral, sobretudo na realização de alguns gêneros, como o poema, o qual evoca o trabalho com a entonação, a elocução, o gestual e a postura corporal. Já a atividade de apresentação de trabalhos, enquadra-se na categoria dos gêneros orais formais da esfera pública (DOLZ, SCHNEUWLY e HALLER, 2004), os quais, como já discutimos, devem ser alvo de reflexão sistemática para o desenvolvimento da expressão oral dos alunos. As atividades de debate e exposição de ideias também foram explicitadas por duas das seis professoras.

As respostas das professoras ainda incluíram "atividades" não categorizadas aqui, tais como "sistematização de conteúdo" (P3) e "chamar a atenção dos alunos" (P4). Todavia, por se tratarem, na verdade, de estratégias didáticas em que o uso do oral se faz presente, mas não como alvo de reflexão sistemática, optamos por não considerá-las para fins de análise neste estudo. Assim, apenas em algumas das atividades mencionadas pelas professoras o oral poderia, de fato, ser tomado como objeto de ensino sistemático. São elas: debate, leitura em voz alta e apresentação de trabalho.

A professora P1 que, na ocasião da coleta, atuava numa turma do $4^{\circ}$ ano, foi a selecionada para a etapa seguinte da pesquisa, uma vez que duas das atividades mencionadas por ela poderiam, se bem exploradas 


\begin{tabular}{|c|c|c|}
\hline $\begin{array}{r}\text { Aline Lopes da } \\
\text { Fonseca }\end{array}$ & \multicolumn{2}{|c|}{ como categorias de análise, as quais serão detalhadas a seguir: } \\
\hline & \multicolumn{2}{|c|}{ 6.1. A atividade de apresentação de trabalho } \\
\hline Gustavo & \multirow{5}{*}{\multicolumn{2}{|c|}{$\begin{array}{l}\text { Aqui, apresentamos algumas de nossas reflexões sobre a forma de or- } \\
\text { ganização do trabalho com o oral e as habilidades exploradas por P1 } \\
\text { durante a realização da atividade de apresentação de trabalho na sala de } \\
\text { aula. A priori, elaboramos um quadro síntese da atividade realizada } \\
\text { pela docente: }\end{array}$}} \\
\hline Henrique da & & \\
\hline Silva Lima & & \\
\hline & & \\
\hline Sara Talita & & \\
\hline \multicolumn{3}{|l|}{ Cordeiro Vilela } \\
\hline & \multicolumn{2}{|c|}{ QUADRO 2: síntese da atividade "apresentação de trabalho" } \\
\hline \multirow{8}{*}{494} & \multirow{2}{*}{\multicolumn{2}{|c|}{ Atividade de Apresentação de trabalho }} \\
\hline & & \\
\hline & $1^{\circ}$ Momento & Disposição dos grupos na sala de aula; \\
\hline & $2^{\circ}$ Momento & Organização do material didático; \\
\hline & $3^{\circ}$ Momento & Início da apresentação do primeiro grupo do trabalho; \\
\hline & $4^{\circ}$ Momento & Apresentação do segundo grupo; \\
\hline & $5^{\circ}$ Momento & Apresentação do terceiro grupo; \\
\hline & $6^{\circ}$ Momento & Considerações da professora sobre os trabalhos. \\
\hline
\end{tabular}

Fonte: elaborado pelos autores.

O trabalho com o oral se deu no âmbito do componente curricular de Geografia. A aula teve seu início com uma leitura deleite, com um trecho de o "Diário de Anne Frank", feita por P1. Em seguida, a professora solicitou que os grupos se reunissem para realização dos cartazes que eles utilizariam na apresentação com base no que haviam pesquisa$\mathrm{do}^{7}$. No primeiro momento, em círculos, os alunos se organizaram para a elaboração dos cartazes e para estudarem mais um pouco o assunto do trabalho: as regiões do país e suas características.

No segundo momento, a professora instalou a caixa de som com o microfone e, depois de testar os equipamentos, pediu para começar as apresentações. Escreveu no quadro o nome das regiões e começou

\footnotetext{
6 O Diário de Anne Frank é um livro escrito por Anne Frank, uma jovem judia vítima do Nazismo. o diário relata momentos vivenciados por um grupo de judeus confinados num esconderijo durante a ocupação nazista na $2^{\mathrm{a}}$ Guerra Mundial.

7 A professora havia solicitado anteriormente aos alunos uma pesquisa sobre as regiões brasileira e suas características.
} 
a chamar nominalmente os grupos. No terceiro momento, os grupos iniciaram as apresentações. Antes, porém, a professora explicou como deveriam iniciar o trabalho. Vejamos:

Exemplo 1:

P1- primeiro você vai dizer "boa tarde".... você é do grupo de quê?

Aqui, percebemos que a professora demonstra uma preocupação com as formas ritualizadas de alguns gêneros orais da esfera pública formal. Ou seja, numa apresentação pública, é importante que se faça uma saudação e uma apresentação inicial de quem fala. Do mesmo modo, é recomendado que se mantenha uma postura e um tom de voz adequado ao público-alvo e à situação comunicativa. Nesse sentido, a realização dessa atividade requer, Atividades com o oral nos anos iniciais do ensino fundamental segundo Melo e Cavalcante (2006), parâmetros que envolvem tanto aspectos extralinguísticos quanto aspectos paralinguísticos e cinésicos.

Durante a apresentação, a professora ainda fez algumas interrupções e questionamentos relacionados ao assunto apresentado pelo grupo com o intuito de ajudar os alunos a explorarem mais alguns conteúdos da apresentação, quando, por exemplo, perguntou sobre a cultura, as comidas típicas e o clima da região.

No quarto momento, o segundo grupo de alunos, que ficou com a região centro-oeste, foi para frente da sala, afixou uma cartolina no quadro e deu início a apresentação. A professora, mais uma vez, fez algumas interrupções, pois um dos alunos estava falando muito rápido, como mostra o recorte da fala abaixo:

\section{Exemplo 2:}

P1- espere! Fale devagar que ninguém aqui vai rir de você. Você fez muito bem o seu trabalho. Diga o nome dos estados e capitais.

Aqui, P1 solicita que o aluno fale de forma pausada, o que evidencia uma preocupação da professora com a elocução, um aspecto paralinguístico da fala (MELO e CAVALCANTE, 2006), uma vez que o aluno estava falando de forma muito rápida e atropelada, dificultando a compreensão por parte dos demais colegas e da própria docente.

Ao longo da apresentação, P1 ainda fez algumas intervenções, solicitando aos demais componentes do grupo que falassem um pouco mais alto. Nesse momento, percebemos a preocupação da docente com outro 

Aline Lopes da
Fonseca
Gustavo
Henrique da
Silva Lima
Sara Talita
Cordeiro Vilela
496 ção oral proposta: a necessidade de utilizar uma entonação de voz que seja adequada ao público-alvo. No quinto momento, houve a apresenta- ção do terceiro e último grupo. Os alunos falaram sobre a região Norte e, já no início da apresentação, a professora criticou o fato de o grupo não ter confeccionado um cartaz e não ter estudado sobre o tema. Por fim, após a apresentação dos grupos, a professora teceu comentários sobre os trabalhos:
Exemplo 4:
P1- Teve pessoas aqui que souberam falar bem, mas outras que não, porque no meio da aula fica conversando falando alto, aí pega um papel não sei com que letra que não consegue nem ler, pessoas que leem muito bem aí eu não... entende!?.....
Vocês melhoraram, pois tinham mania de ficar de costas lendo cartaz, mas eu preciso de outra melhora.

aspecto do oral, o paralinguístico, importante na situação de comunica-

Mais uma vez, percebemos a preocupação de P1 com aspectos paralinguísticos, como a entonação ("souberam falar bem"), e cinésicos da fala, como a postura de alguns durante a apresentação ("Vocês melhoraram, pois tinham mania de ficar de costas lendo o cartaz").

A seguir, discorreremos sobre a outra atividade realizada pela professora na sala de aula: a leitura em voz alta.

\subsection{A atividade de leitura em voz alta}

A partir de agora, descreveremos um pouco sobre como se deu a realização da atividade "leitura em voz alta" por P1 e quais dimensões do oral foram exploradas por ela na sala de aula. Tal como fizemos com a atividade anterior, apresentaremos, a princípio, um quadro síntese da atividade realizada em sala: 
QUADRO 3: Síntese da atividade "leitura em voz alta"

\begin{tabular}{|l|l|}
\hline \multicolumn{2}{|c|}{ ATIVIDADE DE “LEITURA EM VOZ ALTA” } \\
\hline $1^{\circ}$ Momento & Disposição dos grupos na sala de aula; \\
\hline $2^{\circ}$ Momento & Início da leitura em voz alta do primeiro grupo sobre a velha cuca; \\
\hline $3^{\circ}$ Momento & Leitura em voz alta do segundo grupo, sobre o Iasi-Iaterê é Saci-Pererê; \\
\hline $4^{\circ}$ Momento & leitura em voz alta do terceiro grupo sobre a Curupira; \\
\hline $5^{\circ}$ Momento & leitura em voz alta do quarto grupo sobre o Boitatá; \\
\hline $6^{\circ}$ Momento & leitura em voz alta do quinto grupo sobre o Caipora; \\
\hline $7^{\circ}$ Momento & leitura em voz alta do sexto grupo sobre a Vitória-Régia. \\
\hline
\end{tabular}

Fonte: elaborado pelos autores.

A segunda atividade observada teve seu início com uma leitura deleiAtividades com o oral nos anos iniciais do ensino fundamental te da professora, mais um trecho do "Diário de Anne Frank". Assim como a leitura deleite da aula anterior, não houve articulação com o tópico da aula. Em seguida, a docente pediu que os grupos se organizassem para a preparação da leitura em voz alta. Cada grupo ficou responsável pela leitura de uma lenda brasileira do livro "A lua refletiu lendas no Brasil", de autoria de João Collares e Cristina Collares, que faz parte da coleção Nas Ondas da Leitura ${ }^{8}$

Logo depois, a professora instalou os equipamentos (o microfone e o som) e, em seguida, solicitou que os alunos dessem início às apresentações. O primeiro grupo iniciou os trabalhos com um dos alunos assumindo o papel de narrador, enquanto outro aluno interpretava o papel dos personagens e um terceiro segurava um desenho produzido pelo grupo que representava o personagem da lenda. A lenda apresentada foi A velha cuca. Todos da sala entraram no clima da história, fizeram a roda e dançavam e cantavam uma cantiga de roda $A$ velha cuca no momento em que eram solicitados. Por fim, todos se sentaram e o leitor narrador concluiu a história. Durante essa apresentação, houve algumas intervenções por parte da docente, tais como:

\section{Exemplo 5:}

P1- devagar, leia o título sem pressa.

P1-Ohhh... ela tem uma pança enorme capaz de caber uma criança dentro. Você esta lendo rápido, inventado palavras...

8 Projeto de incentivo à leitura desenvolvido por uma editora nacional em parceria com a Secretaria de Educação Municipal de Garanhuns-PE. 
Aqui, observamos, mais uma vez, a preocupação da docente com os aspectos paralinguísticos da fala (MELO e CAVALCANTE, 2006) e com

Aline Lopes $\mathrm{da}$

Fonseca

Gustavo

Henrique da

Silva Lima

Sara Talita

Cordeiro Vilela

498

outra dimensão importante, a nosso ver, para o trabalho com o oral: a oralização de textos escritos. Os grupos que se apresentaram na sequência seguiram o mesmo padrão de apresentação do primeiro grupo. A professora continuou a fazer algumas interrupções durante as apresentações, solicitando aos alunos que tivessem um pouco mais de atenção ao ritmo de voz (falavam muito rápido) e que falassem pausadamente, de acordo com a pontuação. Vejamos:

Exemplo 6:

P1- O cabelo vermelho como fogo, ponto. Você tem que falar respeitando a pontuação.

Em outros momentos, P1 fez novas interrupções para chamar atenção dos alunos quanto aos "erros" de pronúncia de algumas palavras ou expressões na fala ou até mesmo de aspectos gramaticais, tal como podemos ver abaixo:

Exemplo 7:

P1- Olha o verbo!

P1- Leia alto! Você estava falando baixo!! Agora vem uma pergunta. Caderno de anotações... olhe a concordância.

Todavia, é importante destacar aqui que, de modo geral, os alunos se mostraram tímidos e receosos durante as apresentações, evidenciando, por conseguinte, a dificuldade que eles ainda tinham de "falar em público". Tal aspecto parece evidenciar que essa habilidade não é ensinada na sala de aula, embora seja sempre exigida dos alunos.

\section{Considerações Finais}

O presente estudo se propôs a apresentar um recorte sobre as práticas de oralidade nos anos iniciais do ensino fundamental, evidenciando indícios de como ocorre esse ensino. Durante as atividades de apresentações dos trabalhos e de leitura em voz alta, verificamos que a professora teve a preocupação em fazer algumas correções não só de postura, mas também acerca de algumas formas de ritualização, além de elocução, entonação de voz e pausa da fala, visando auxiliar os alunos a terem 
um melhor desempenho na expressão oral. Esse dado abre espaço para outras reflexões, como, por exemplo, a necessidade de se pensar sobre o lugar que o eixo da oralidade tem ocupado nos processos de formação (inicial e continuada) docente, bem como nos documentos oficiais orientadores do ensino e nos materiais didáticos utilizados pelos professores em sala de aula.

Finalizamos reforçando que inúmeras dificuldades envolvendo o ensino da oralidade ainda precisam ser superadas. Para tal, são necessárias políticas públicas de formação de professor que desmistifiquem algumas crenças (equivocadas) sobre o trabalho com a oralidade, ao mesmo tempo em que vislumbrem alternativas didático-pedagógicas para lidar com o ensino do oral de forma mais sistemática, alçando-o a um patamar de igualdade e relação aos demais eixos de ensino de língua.

Atividades com o oral nos anos iniciais do ensino fundamental

\section{REFERÊNCIAS}

ANTUNES, Irandé. Aula de português: encontro e interação. São Paulo: Parábola Editorial, 2003.

ÁVILA, Ewerton; NASCIMENTO, Gláucia e GOIS, Siane. Ensino de oralidade revisitando documentos oficiais e conversando com professores. IN: LEAL, Telma Ferraz e GOIS, Siane (org.). A oralidade na escola: A investigação do trabalho docente como foco de reflexão. Belo Horizonte: Autêntica, 2012.p.37-56.

BRASIL. Secretaria de Educação Fundamental. Parâmetros Curriculares Nacionais: Língua Portuguesa. Brasília: 1997.

Secretaria de Educação Fundamental. Parâmetros Curriculares Nacionais: Língua Portuguesa. Brasília: 1998.

COSTA-MACIEL, Debora Amorim Gomes da. Os saberes docentes para o ensino da oralidade: o que sabem os professores e como compreendem as atividades propostas pelos livros didáticos de língua portuguesa? Tese de doutorado em Educação. Recife, UFPE, 2011. 
COSTA-MACIEL, Débora; BILRO, Fabrini. Afinal, a oralidade pode ser ensinada? o que propõem os livros didáticos de língua

Aline Lopes $\mathrm{da}$

Fonseca

Gustavo

Henrique da

Silva Lima

Sara Talita

Cordeiro Vilela

500 portuguesa?In: $30^{a}$ Reunião Nacional da ANPED - no período de 09 de fevereiro á 9 de março de 2015,Florianópolis. Disponível em: $<$ http://www.anped.org.br/sites/default/files/trabalho-gt10-4054.pdf>. Acesso em: 19 jun. 2016.

COSTA-MACIEL, Débora; BARBOSA, Maria Lucia. “Ah, eu acho a oralidade muito importantíssima, meu deus!" A A propósito da prática docente no ensino da oralidade. In: $35^{\text {a }}$ Reunião Nacional da ANPED - no período 21 a 24 de outubro de 2012, Porto de Galinhas- PE. Disponível em: <http://www.anped.org.br/sites/default/ files/gt10-2272_int.pdf>. Acesso em: 19 jun. 2016.

MARCUSCHI, Luiz Antônio. Oralidade e Ensino de Língua: uma questão pouco “falada". In: DIONISIO, Angela Paiva; BEZERRA, Maria Auxiliadora. O livro didático de português: múltiplos olhares (org). 3. ed. Rio de Janeiro: Lucena, 2005.

DOLZ, Joaquim; SCHNEUWLY, Bernard. O oral como texto: como construir um objeto de ensino. In: SCHNEUWLY, Bernard; DOLZ, Joaquim. Gêneros orais e escritos na escola. Campinas: Mercado de Letras, 2004.

DOLZ, Joaquim; SCHNEUWLY, Bernard; HALLER, Sylvie. O oral como texto: como construir um objeto de ensino. In: SCHNEUWLY, Bernard; DOLZ, Joaquim e col. Gêneros orais e escritos na escola. Tradução e organização de Roxane H. R. Rojo e Glaís S. Cordeiro. Campinas, SP: Mercado de Letras, 2004. p. 149-214.

LUDKE, M; ANDRÉ, MEDA. Pesquisa em educação: abordagens qualitativas. São Paulo, EPU, 1986.

MAGALHÃES, Tânia. Concepções de Oralidade: a teoria nos PCN e PNLD e a prática nos livros didáticos. In: $30^{\mathrm{a}}$ Reunião Nacional da ANPED - no período de 07 a 10 de outubro de 2007, Caxambu/MG. Disponível em: <http://www.anped.org.br/reunioes/30ra/trabalhos/ GT10-3320-Int.pdf>. Acesso em: 19 jun. 2016. 
MARCUSCHI, Luiz Antônio. Da fala para escrita: atividades de retextualização. 8 ed. São Paulo: Cortez,2003.

Da fala para escrita: atividades de retextualização. 4 ed. São Paulo: Cortez, 2007.

Oralidade e letramento como práticas sociais. IN:MARCUSHI, Luiz Antônio; DIONISIO, Angela Paiva (Orgs). Fala e Escrita. $1^{\mathrm{a}} \mathrm{Ed}$, Belo Horizonte: Autêntica, 2007., p.31-56.

Produção textual, análise de gêneros e compreensão. São Paulo, parábola Editorial, 2008 p.186-199

Atividades com o oral nos anos iniciais do ensino fundamental

MELO, Cristina Teixeira Viera e CAVALCANTE, Marianne Bezerra. Superando os obstáculos de avaliar a oralidade. In: MARCUSCHI, Beth e LIVIA, Suassuna (org.). Avaliação em Língua Portuguesa: contribuições para a prática pedagógica. Belo Horizonte: Autêntica, 2006.

SCHNEUWLY, Bernard; DOLZ, Joaquim. Os gêneros escolares - das práticas de linguagem aos objetos de ensino. In: SCHNEUWLY, Bernard; DOLZ, Joaquim e col. Gêneros orais e escritos na escola. Tradução e organização de Roxane H. R. Rojo e Glaís S. Cordeiro. Campinas, SP: Mercado de Letras, 2004. p. 71-91.

SCHNEUWLY, Bernard; DOLZ, Joaquim; HALLER, Sylvie. O oral como texto: Como Construir um objeto de ensino. In: SCHNEUWLY, Bernard; Bernard; DOLZ, Joaquim. Gêneros orais e escritos na escola. Tradução e organização de Roxane H. R. Rojo e Glaís S. Cordeiro. Campinas, SP: Mercado de Letras, 2004. p. 125-158. 
